\title{
Pro-Environmental Awareness and Behaviors on Campus: Evidence from Tianjin, China
}

\author{
Liping Fu ${ }^{1}$, Ye Zhang ${ }^{1}$, Xiong Xiong ${ }^{1,2}$, Yin Bai ${ }^{1 *}$ \\ ${ }^{1}$ College of Management and Economics, Tianjin University, Tianjin PR CHINA \\ ${ }^{2}$ China Center for Social Computing and Analytics, Tianjin University, Tianjin, PR CHINA \\ Received 7 July 2017 - Revised 24 August 2017 - Accepted 7 October 2017
}

\begin{abstract}
China has promoted green campuses for decades. To better explore the current extent of pro-environmental awareness and behaviors of types of stakeholders (student, faculty members, and administrators) on campus, this study investigated the relationship between pro-environmental awareness and pro-environmental behaviors along with the influences of motivators, barriers, and culture (face (reputation) and group pressure). A questionnaire survey was conducted with a sample of the three types of stakeholders at Tianjin University, one of the largest academic institutions and the earliest to implement green campus development initiatives in China. Structural equation modeling tested a causal model of awareness, behaviors, and other explanatory variables. The results found that pro-environmental behaviors were more likely than awareness and the respondents engaged in private more than in public proenvironmental behaviors. Chinese social and cultural factors influenced proenvironmental behavior, particularly among the administrators, which informs our understanding of the reasons for the awareness-behavior gap. China's universities focus on eco-technology and energy management rather than on dissemination and publicity. The results suggest that advancing a pro-environmental cultural atmosphere and a consistent sustainability policy might significantly foster pro-environmental behaviors on university campuses.
\end{abstract}

Keywords: environmental awareness, environmental behavior, cultural norms, structural equation model, stakeholder

\section{INTRODUCTION}

Since the beginning of China's economic reform and opening-up in 1978, economic development and environmental protection have been two key emphases in China, although which issue to prioritize barely reached consensus until President $X_{i}$ Jinping systematically elucidated the spiritual meaning of the "New Normal" in the Asia Pacific Economic Cooperation on December 9, 2014. He emphasized a new guiding ideology of slowing the economic growth and promoting a green, low-carbon, and sustainable type of development. ${ }^{1}$ This big change challenged numerous societal functions and activities in business, government, and academia (Baas and Hjelm, 2015).

Universities are the most likely of these societal domains to implement the New Normal policy because "the future leaders, decision-makers and intellectuals of the social, political, economic, and academic sectors are created, formed, and shaped within the world's higher education institutions" (Lozano, 2006). Clearly, universities are becoming the backbone of China's sustainable and responsible development (Dagiliute and Liobikiene, 2015; Wang et al., 2013; Zsoka et al., 2013). Universities have devised initiatives to study their influences on the environment (Lozano, 2010; Lukman et al., 2013; Tarah, 2007), and many studies have focused on student perceptions of

${ }^{1}$ http:/ / theory.people.com.cn/n/2014/1212/c40531-26194262.html

(c) Authors. Terms and conditions of Creative Commons Attribution 4.0 International (CC BY 4.0) apply. 


\section{Contribution of this paper to the literature}

- The paper provides a multi-stakeholders perspective, including the internal stakeholders of students, teaching faculty, and administrative staff to improve understanding of the extent of environmental protection at Chinese universities.

- The paper reconsiders early work on the awareness-behavior gap and adds in four external factors in terms of motivators, barriers, face (reputation), and group pressure on three types of stakeholders on campus.

- The results show that advancing a pro-environmental cultural atmosphere and a consistent sustainability policy might significantly foster pro-environmental behaviors on university campuses.

environmental initiatives, such as curricula on environmental education and extracurricular activities (Azucena Vicente-Molina et al., 2013; Isljamovic et al., 2011; Oguz et al., 2010; Rodriguez-Barreiro et al., 2013; Zsoka et al., 2013).

It is rare that studies focus on the variation in perceptions of the influence of the environment on university campuses. However, universities are micro-societies comprising a variety of types of stakeholders that include students, faculty, and administrative staff, and the members of these groups interact with each other and influence each other. However, studies on environmental topics on campus mainly focus on one type of stakeholder, such as students or faculty members, instead of taking a panoramic view across the types of stakeholders.

Some studies have applied a multi-stakeholder approach to other conditions at universities. For example, Clauss-Ehlers and Parham (2014) pointed out that universities are being challenged by shifting academic, social, and emotional climates on campuses and that campus stakeholders must navigate continually evolving educational landscapes. Emelyanova and Voronina (2014) emphasized that a key to successful and efficient use of Learning Management Systems is the way that campus stakeholders take advantage of this learning tool. However, we should consider the power of policymaking on and supervision of environmental issues at universities. For example, student engagement should be key to creating an environment of meaningful engagement between students and staff (Carey, 2013). Yuan et al. (2013) focused on cognitive depth and the green university from the perspective of external stakeholders (alumni and students' parents).

Following previous studies arguing that study sites like universities should be researched as multi-stakeholder units of increasing sophistication and complexity, this study examined the relationships between environmental awareness and environmental behavior from a multi-stakeholder perspective. This perspective included the internal stakeholders of students, teaching faculty, and administrative staff to improve understanding of the extent of environmental protection at Chinese universities. In addition, the distribution of management functions was considered to explore the policy-making power distribution for and supervision of environmental concerns at universities. The study's goals were accomplished by comparing the extents of pro-environmental awareness and pro-environmental behaviors among the types of stakeholders. The study's results suggest ways to improve awareness and increase behaviors, which are proposed according to stakeholder group.

The structure of this paper is as follows. Section 2 presents a review of the literature on the previous relevant studies and the seven hypotheses tested in the analysis. Section 3 explains the theoretical framework used to interpret the findings. Section 4 describes the study's objectives, study site, sample selection, and methods of analysis. Section 5 reports the results of the descriptive analysis and the structural equation model's (SEM) estimations, followed by discussion and conclusions (Sections 6 and 7). Recommendations are offered for policymakers and university leaders on developing and advancing a pro-environmental atmosphere and for consistent sustainability to foster pro-environmental behaviors on green campuses.

\section{LITERATURE REVIEW}

\section{Pro-environmental Behaviors}

Many previous studies have examined the environmental problems caused by human activities (Koger and Winter, 2011). In these studies, human activities to protect the environmental are referred to as "pro-environmental behavior," "green behavior," "environment-friendly behavior," or "low-carbon behavior." This study used "proenvironmental behavior" to refer to human activities to protect the environment. In addition, pro-environmental behaviors vary and have been categorized. Stern (2000) divided pro-environmental behavior into two categories: private pro-environmental behavior (e.g., purchase, use, and disposal of personal products or services) and public pro-environmental behavior (e.g., discourse on environmental issues, pro-environmental policies, and encouraging people to participate in pro-environmental activities). Sizable literatures have focused on particular types of proenvironmental behaviors, such as energy conservation and habits (Martinsson et al., 2011; Steg, 2008), student responses to saving energy (Cotton et al., 2016), travel modes (Axsen and Kurani, 2012), battery collection (Sun et 
al., 2015), and recycling efficiency (Barr, 2007). This study applied Stern's (2000) broad categories to a campus setting to contrast private pro-environmental behaviors and public pro-environmental behaviors. Furthermore, in addition to the behaviors investigated by the previous studies, this study analyzed pro-environmental behaviors regarding reuse of wooden chopsticks and two-sided or single-sided printing because these are very common relevant activities on campuses.

\section{Pro-environmental Awareness}

Some previous studies argued that the term "environmental awareness" is a multidimensional construct (Abdul-Wahab, 2010; Zsoka, 2008). Pro-environmental knowledge, pro-environmental values, and proenvironmental attitudes are the most frequently mentioned components of pro-environmental awareness. These components are considered interactive (Bamberg, 2003) because, for example, increased environmental knowledge might increase concerns and awareness, which might lead to personal behavioral changes (Creech et al., 2009). Proenvironmental "values" have been defined as important life goals or standards that guide a person's life (Rokeach, 1973). Within the ecological worldview framework, values could be one of two types: biospheric (the global ecological system that integrates all life) or anthropocentric (ecology that privileges human benefits) (Thompson and Barton, 1994). Many of these studies have featured variables that measure internal factors expected to influence pro-environmental behaviors and highlight an environmental awareness that combines values with attitudes, feelings, and emotional involvement (Kollmus and Agyeman, 2002; Lin and Huang, 2012). However, values might be distinct from environmental awareness because they function as a coordinated scheme and, therefore, might be determinants of attitudes and behaviors (Olson and Zanna, 1993). Based on this reasoning, the following hypothesis was devised.

H1: Pro-environmental values positively influence pro-environmental attitudes.

Pro-environmental attitudes have been positively and negatively related to actual situations and objects and conceptualized as evaluations of an object (Bohner and Dickel, 2011). Numerous studies have verified that attitudes are strong determinants of behaviors (Barber et al., 2009; Paco and Lavrador, 2017; Polonsky et al., 2012), and that attitudes are strong influences on pro-environmental knowledge and behaviors. Attitudes might create judgments and emotions that focus on good or bad, or desirable or undesirable, activities. On a university campus, the objects referred to are the environmental judgments made by three groups aimed to evaluate their cognition to environmental status, the growing tendency of environmental deterioration and willingness to change, like the attention to environmental protection for laboratory exhaust emission and waster liquid. The following hypothesis was developed based on this reasoning.

H2: Pro-environmental attitudes positively influence pro-environmental behaviors.

Pro-environmental knowledge generally has included factual knowledge on environmental topics, definitions, and policies and action-related knowledge on skills and activities (Schahn and Holzer, 1990). It is widely accepted that increases in pro-environmental knowledge leads to increases in intentions to act on pro-environmental behaviors because people must first understand their needs and be aware of the urgency and significance of a proenvironmental lifestyle before they can take pro-environmental actions (Abrahamse et al., 2007; Paco and Lavrador, 2017; Raymond et al., 2010). However, whether pro-environmental knowledge influences behavior has been criticized because of the unstable relationship between attitudes and behaviors. For example, Cotton et al. (2016) claimed that university students had strong attitudes about environmental issues, but their knowledge on and willingness to take the energy-saving steps were limited. Therefore, this study proposed the following hypothesis, which addresses pro-environmental behaviors directly and indirectly.

H3: Pro-environmental knowledge positively and directly influences pro-environmental behaviors and indirectly influences pro-environmental behaviors through its influence on pro-environmental values and pro-environmental attitudes.

\section{The Effects of Motivators, Barriers, and Cultural Norms on Pro-Environmental Behaviors}

Based on the debate regarding the effects of changed individual awareness on environmental behavior, several external factors have been found to be influential. The literature on the value-action gap (Van Raaij and Verhallen, 1983) indicates that the extent of pro-environmental behavior is often less than a person's awareness because of contextual or personal factors that serve as barriers to such behavior. Some studies have discussed barriers that might interfere with pro-environmental behaviors, such as lack of skill or time, inconvenience, and so on (Barr, 2007; Chan et al., 2010; Fernandez-Manzanal et al., 2015; Jager, 2006; Zsoka et al., 2013). Fernandez-Manzanal et al. (2015) proposed four barriers that present significant difficulties to environmental engagement, two of which were strong internal or external barriers, such as lack of theoretical or practical training and lack of environmental policy, and two of which were weak internal or external barriers, such as lack of leadership and lack of perceived importance. On the other hand, motivators, such as supportive policy or financial rewards, might encourage pro- 
environmental behaviors (Bai and Liu, 2013). For example, individuals tended to make green choices when offered incentives to do so, such as a financial reward (Maniatis, 2016; Sabbaghia et al., 2016; Wright et al., 2008). Moreover, studies have considered the importance of the roles of the relevant laws and regulations to influence proenvironmental behaviors (Ozaki and Sevastyanova, 2011; Steg and Vlek, 2009; Wright, 2010). Based on the previous studies findings, the following hypotheses were developed.

H4: There are barriers that negatively affect pro-environmental behaviors.

H5: There are motivations that positively affect pro-environmental behaviors.

Some previous studies have suggested that awareness and behavior might be influenced by family, friends, and colleagues as well as by cultural values and relevant policies (Bayulken and Huisingh, 2015; Chan et al., 2010; Daae and Boks, 2015; Sidiras and Koukios, 2004). Most strikingly, problems related to the concept of "face" 2 and group pressures have been found important to individual behaviors in Chinese society. As early as 1894, American missionary Authur H. Smith (1894) pointed out the importance of face in Chinese society in his book entitled Chinese Characteristics.

Many domestic and foreign scholars have further addressed and considered the implications of face. Brown and Levinson (1987) defined "public self-image" with features that were positive and negative regarding face. Spencer-Oatey (2002) proposed that the notion of face has social attributes involving ability and morality. Wang et al. (2005) focused on the nature of face, opining that it originates in individuals' desires to maintain a positive sense of status and to obtain positive judgments from others. Hu and Wang. (2014) classified face as virtual face (e.g., conspicuous consumption and formalism) or actual face (e.g., concrete achievements derived from personal efforts). Face also demonstrates an individual's self-identity and social identity. Regarding the association of face with proenvironmental behaviors, Hu and Wang. (2014) identified purchase behavior (i.e., purchasing environmentfriendly products), use behavior (i.e., prevention of waste), and disposal behavior (i.e., recycling).

The relevant literature implies that the public tends to be significantly influenced by awareness of face in everyday life. Behavioral science has suggested that the behaviors to which people ultimately commit are determined by several factors, such as attitudes, habits, and contexts. Stern (2000) developed the attitude-behaviorcontext model, which proposed that behavior is caused by the mutual effects of attitudes and contexts. Many previous studies have found that psychological factors motivated the public's face-oriented consuming, such as consumption that promotes face, maintains face, and/or prevents the loss of face (Chan, R.Y.K., 2001; Zhu, et al, 2013). Therefore, in the Chinese context, the driving influence on consumption is likely to be face, and, based on these previous studies' findings, the following hypothesis was devised.

H6: Attention to face negatively influences pro-environmental behaviors.

Social factors also have been found to strongly influence pro-environmental intentions and behaviors. "Economics, sociology, anthropology and psychology" were the determinants of pro-environmental behaviors and group pressure was a variable that scholars focused on as well (Clark et al., 2003; Turaga et al., 2010). Group pressure generally refers to an individual's perceived mental pressure experienced when that individual feels conflict with a particular group's criterion. The likelihood that an individual will conform might relate to the proportion of group members that had already done so. Further, an individual's inclination to act in accord with others' actions or beliefs might relate to the extent to which that individual wants to conform or on information obtained from others. ${ }^{3}$

Group pressure has been found to significantly influence the development of individual environmental behaviors. However, whether or not the influence of group pressure is direct has been controversial. For example, Barr (2003) argued that group pressure influences individual pro-environmental behaviors through its moderating influence on pro-environmental awareness. However, Ajzen (1985, 1991), Yu (2009), and others have argued that behavior is directly influenced by the energy-saving habits of family and/or friends. Unwillingness to change (Lozano, 2006) has been highlighted because it costs time and effort to persuade others to participate in proenvironmental behaviors, such as "taking stairs instead of the elevator" and "setting a warmer air conditioner temperature". The following hypothesis was devised based on these previous studies.

H7: Group pressure negatively influences pro-environmental behaviors.

The seven hypotheses tested in this study are summarized in Table 1.

\footnotetext{
2 https://en.wikipedia.org/wiki/Face_(sociological_concept)

3 https://en.wikipedia.org/wiki/Peer_pressure
} 
Table 1. Hypothesized relationships

\begin{tabular}{|c|c|c|}
\hline Hypothesis & Explanatory Variable & Hypothetical Outcome \\
\hline \multirow{4}{*}{ 1. Knowledge } & Values & + \\
\hline & Attitudes & + \\
\hline & Public behaviors & + \\
\hline & Private behaviors & + \\
\hline 2. Values & Attitudes & + \\
\hline \multirow{2}{*}{ 3. Attitudes } & Public behaviors & + \\
\hline & Private behaviors & + \\
\hline \multirow{2}{*}{ 4. Motivators } & Public behaviors & + \\
\hline & Private behaviors & + \\
\hline \multirow{2}{*}{ 5. Barriers } & Public behaviors & - \\
\hline & Private behaviors & - \\
\hline 6. Face & Private behaviors & - \\
\hline 7. Group pressure & Public behaviors & - \\
\hline
\end{tabular}

\section{MATERIALS AND METHODS}

\section{Research Objectives}

This study's first objective was to improve our understanding of pro-environmental awareness and proenvironmental behaviors among types of stakeholders at universities. The goal was to identify pro-environmental awareness and pro-environmental behavioral differences among the types and identify the mechanisms of green campus development.

However, Tan et al. (2014) pointed out in their review of the progress of green campuses in China that China's green campus development focuses on technology for energy facilities with a strong emphasis on enforcement, whereas foreign universities pay relatively more attention to spreading the ideas. Therefore, China should first learn the status of pro-environmental awareness and pro-environmental behaviors on campuses and, then, develop the technologies. Therefore, the second objective of this study is that its findings provide a general snapshot of proenvironmental awareness and pro-environmental behaviors representing most of China's universities. This snapshot might distinguish between the consequences of top-design foreign universities' trends and the bottomfocused progress in China mentioned above and foreign as well as to illustrate the reasons and countermeasures.

Third, based on the results of the analysis of the relationship between pro-environmental awareness and behaviors and the influencing factors, the study aims to be positioned at the crux of the problem to put forward concrete policies.

\section{Study Site}

The study site was in Tianjin, one of four municipalities directly under the control of the Chinese central government. Tianjin University was chosen because it was one of the first institutions directly under the control of the Chinese Ministry of Education to develop a green campus. As a core member of the China Green University Network (CGUN), supported by the Chinese government (China Green University Network, 2013), Tianjin University has made significant advancements in technological renovation and transformation of its energy-saving heating system. Shandong University is another member of CGUN that has implemented many such initiatives, such as energy-saving and water-saving measures and waste management (Mu et al., 2015).

\section{Sample}

The survey data were collected by contacting students, faculty members, and administrative staff across the university. Altogether, 1100 individuals at Tianjin University were asked to participate; they were in various departments, such as Environmental Engineering, Chemical Engineering, College of Management and Economics, and Institute of Humanities. A token reward was an incentive for participation. The respondents completed a questionnaire after gaining a brief understanding of the study and agreeing to participate in it. Data collection occurred over three weeks in July of 2014. After screening the 1100 questionnaires collected, 215 were dropped due to incomplete or questionable responses, and $885(80.45 \%)$ valid questionnaires comprised the final sample.

The sample contained 495 males (55.9\%) and 390 females (44.1\%), which indicated a slight difference between genders, perhaps because the cardinal number of male-female ratio of Tianjin University was greater than one. Ages ranged from 17 to 52 years old. About 22.8\% $(n=202)$ was under age 20, $46.3 \%$ was age 20 to 29 , approximately 
Table 2. Characteristics of the sample $(n=885)$

\begin{tabular}{|c|c|c|c|}
\hline & Characteristic & Frequency & Percentage (\%) \\
\hline \multirow{2}{*}{ Gender } & Male & 495 & 55.9 \\
\hline & Female & 390 & 44.1 \\
\hline \multirow{5}{*}{ Age } & $<20$ & 202 & 22.8 \\
\hline & $21-30$ & 410 & 46.3 \\
\hline & $31-40$ & 158 & 17.9 \\
\hline & $41-50$ & 58 & 6.6 \\
\hline & $>50$ & 57 & 6.4 \\
\hline \multirow{3}{*}{ Group } & Student & 487 & 55.1 \\
\hline & Faculty & 147 & 16.6 \\
\hline & Administration & 251 & 28.3 \\
\hline \multirow{3}{*}{$\begin{array}{l}\text { Educational } \\
\text { attainment }\end{array}$} & Undergraduate & 389 & 44 \\
\hline & Master & 355 & 40.1 \\
\hline & Doctoral & 141 & 15.9 \\
\hline \multirow{4}{*}{ Discipline } & Science & 191 & 21.6 \\
\hline & Engineering & 439 & 49.6 \\
\hline & Business & 59 & 6.7 \\
\hline & Humanities & 196 & 22.1 \\
\hline Total & & 885 & 100.0 \\
\hline
\end{tabular}

$17.9 \%$ was aged 30 to $39,6.6 \%$ was aged 41 to 50 , and $6.4 \%$ was aged 51 and 52 . Professional and student status was crucial to this study because the study aimed to compare across types of stakeholders, which included students (at different grade levels), faculty, and administrators. About 55.1\% $(n=487)$ of the sample was students, and faculty and administrative staff were $16.6 \%(n=147)$ and $28.3 \%(n=251)$, respectively. Among the participants, about $44 \%$ held bachelor's degrees, $40.1 \%$ held master's degrees, and $15.9 \%$ had doctorates. Within the university, $21.6 \%$ was in science, $49.6 \%$ was in engineering, $6.9 \%$ was in business, and $21.1 \%$ was in humanities. Table 2 shows that the sample was consistent with the demographic characteristics of the campus.

\section{Questionnaire}

This study considered pro-environmental awareness and behaviors as multidimensional constructs and the questionnaire was prepared accordingly to test the seven hypotheses. The items were chosen based on a review of the relevant literature and on personal interviews. The literature review presented in Section 2 supported categorizing pro-environmental behaviors as private behaviors or public behaviors using six items from Stern (2000).

Interviews were conducted with three people from each group and four additional items inspired by those conversations were added. The new items related to campus life (i.e., take a tissue one piece at a time, buy bottled water, order moderate amounts of food, and engaging in discussions on environmental issues).

We grouped pro-environmental awareness as three aspects: knowledge, attitudes, and values. Proenvironmental knowledge was measured using three items on factual knowledge and two action-related items (Raymond et al., 2010). Pro-environmental values were measured using three items (biospheric, egocentric, and anthropocentric) (Thompson and Barton, 1994). To measure pro-environmental attitudes, eight items was derived from the New Environmental Paradigm (Dunlap et al., 2000) and from a focus group (i.e., laboratory wastewater emissions, willingness to learn environmental news). Knowledge, attitudes, and values were measured using a five-point agreement scale, where $1=$ strongly disagree, $2=$ disagree, $3=$ indifferent, $4=$ agree, and $5=$ strongly agree.

To measure barriers, motivators, and cultural norms, 10 items were adopted from Stern (2000) and through individual interviews with two students and two faculty members. To measure face and group pressure, the selection of indicators was guided by the literature review and the results of a focus group that combined campus life. Three aspects of pro-environmental activities were chosen to indicate barriers, motivators, and cultural norms: recycling plastic bottles, leftovers from treating friends, and overemphasizing life quality. The three behavioral items were scored on five-point scales, where $1=$ never, $2=$ rarely, $3=$ sometimes, $4=$ usually, and $5=$ always.

When the draft of the questionnaire was complete, three experts were invited to examine and edit the items to capture the underlying concepts and to eliminate ambiguity and redundancy. Then, the survey data were subjected to a confirmatory factor analysis (CFA) with VARIMAX rotation to assess validity and to calculate Cronbach's alpha to test reliability. As a rule, CFA loadings of 0.50 or greater were considered significant (Hair et al., 2010), and three items on behaviors and four items on awareness were omitted. The standard Cronbach's alpha is 0.70 or larger (Nunnally, 2010), such that between 0.65 and 0.70 is minimally acceptable, between 0.70 and 0.80 is acceptable, and 
Table 3. Construct validity and reliability of the scaled variables

\begin{tabular}{|c|c|c|c|c|}
\hline Variables & Items & $\begin{array}{l}\text { Factor } \\
\text { loading }\end{array}$ & $\begin{array}{l}\text { Percentage } \\
\text { of variance }\end{array}$ & $\begin{array}{c}\text { Cronbach's } \\
\alpha\end{array}$ \\
\hline \multirow{4}{*}{$\begin{array}{l}\text { Public } \\
\text { pro- } \\
\text { environmental } \\
\text { behavior }\end{array}$} & Encourage classmates and colleagues to save resource & .679 & 8.731 & .815 \\
\hline & Encourage classmates and colleagues to join in tree-planting & .843 & & \\
\hline & Support of environmental policies classmates and colleagues & .823 & & \\
\hline & Discuss environmental issues with others & .728 & & \\
\hline \multirow{4}{*}{$\begin{array}{l}\text { Private } \\
\text { pro-environ } \\
\text { mental } \\
\text { behavior } \\
\end{array}$} & Do not use one-off chopsticks & .658 & 10.744 & .755 \\
\hline & Do not litter & .725 & & \\
\hline & Walk or bike for short trip & .756 & & \\
\hline & Public transportation for long trip & .685 & & \\
\hline \multirow{3}{*}{ Knowledge } & Understand $\mathrm{A} 1-\mathrm{A} 12$ are pro-environmental activities & .710 & 5.569 & .648 \\
\hline & Understand A14-A17 are pro-environmental activities & .757 & & \\
\hline & I believe I know environmental issues well & .655 & & \\
\hline \multirow{2}{*}{ Values } & $\begin{array}{l}\text { Concern about environmental issues mainly for human race } \\
\text { development }\end{array}$ & .716 & 7.319 & .863 \\
\hline & $\begin{array}{l}\text { Concern about environmental issues mainly for natural environment and } \\
\text { ecosystem }\end{array}$ & .734 & & \\
\hline \multirow{4}{*}{ Attitudes } & $\begin{array}{l}\text { Universities could make a huge amount of emissions of greenhouse gas } \\
\text { which lead to disasters. }\end{array}$ & .626 & 7.817 & .672 \\
\hline & Our environment is deteriorating severally. & .671 & & \\
\hline & $\begin{array}{l}\text { If thing continues on this present course, the human race would } \\
\text { experience a disastrous ecological catastrophe }\end{array}$ & .669 & & \\
\hline & $\begin{array}{l}\text { I pay attention to environmental protection for laboratory exhaust } \\
\text { emission and waste liquid. }\end{array}$ & .625 & & \\
\hline \multirow{4}{*}{ Motivators } & Some pro-environmental behavior can cut life expense & .744 & 4.844 & .669 \\
\hline & I will engage more pro-environmental behavior in case of reward policy & .710 & & \\
\hline & I do recycling for money & .693 & & \\
\hline & $\begin{array}{l}\text { I will take pro-environmental behavior due to the corresponding laws } \\
\text { and regulations }\end{array}$ & .585 & & \\
\hline \multirow{4}{*}{ Barriers } & I have not enough skills to live a green life & .723 & 4.188 & .672 \\
\hline & It is difficult to find a way to participate in pro-environmental activities & .694 & & \\
\hline & Most people around me do not care about environmental issues & .676 & & \\
\hline & Most pro-environmental behaviors are inconvenient for me & .632 & & \\
\hline \multirow{3}{*}{ Face } & $\begin{array}{l}\text { After drinking bottled water then collecting them to sell is stingy and } \\
\text { humiliating }\end{array}$ & .746 & 9.983 & .710 \\
\hline & Life needs taste and class & .679 & & \\
\hline & When entertaining friends, no residual food on the table is humiliating. & .706 & & \\
\hline \multirow{2}{*}{$\begin{array}{l}\text { Group } \\
\text { pressure }\end{array}$} & $\begin{array}{l}\text { Choose a saving and environmental way due to conformity (family or } \\
\text { friends take environmental actions) }\end{array}$ & .838 & 3.408 & .582 \\
\hline & Choose a waste way due to the worry of being considered as mean & .735 & & \\
\hline Total & & & 62.600 & .796 \\
\hline
\end{tabular}

between 0.80 and 0.90 is strong. However, because our scales had small numbers of items, we considered close to 0.65 as acceptable, meaning that interpreting the results should be done with caution. Table 3 shows the final dataset comprised of 35 items: 10 pro-environmental behaviors, 11 pro-environmental awareness, four motivators, four barriers, and five cultural variables. The Kaiser-Meyer-Olkin (KMO) test statistic was 0.822, which is acceptable. The factor loadings were 0.553 to 0.835 . The eight factors accounted for $59.5 \%$ of the total variance. Regarding reliability, all of the dimensions were considered acceptable and ranged from 0.582 to 0.863 , and Cronbach's alpha on the entire set of items was 0.729 .

\section{Analytical Strategy}

To prepare for the hypothesis testing, descriptive statistics, factor analysis, and multidimensional scaling were performed on the data. SEM is a widely used statistical approach for testing and estimating causal relationships using a combination of quantitative data and qualitative causal reasoning and it can construct latent variables (Byrne, 2001). This study followed Churchill's (1979) research paradigm and SEM was suited to this study's purposes. Figure 1 provides a detailed model of the constructs, their components, and the hypothesized relationships. 


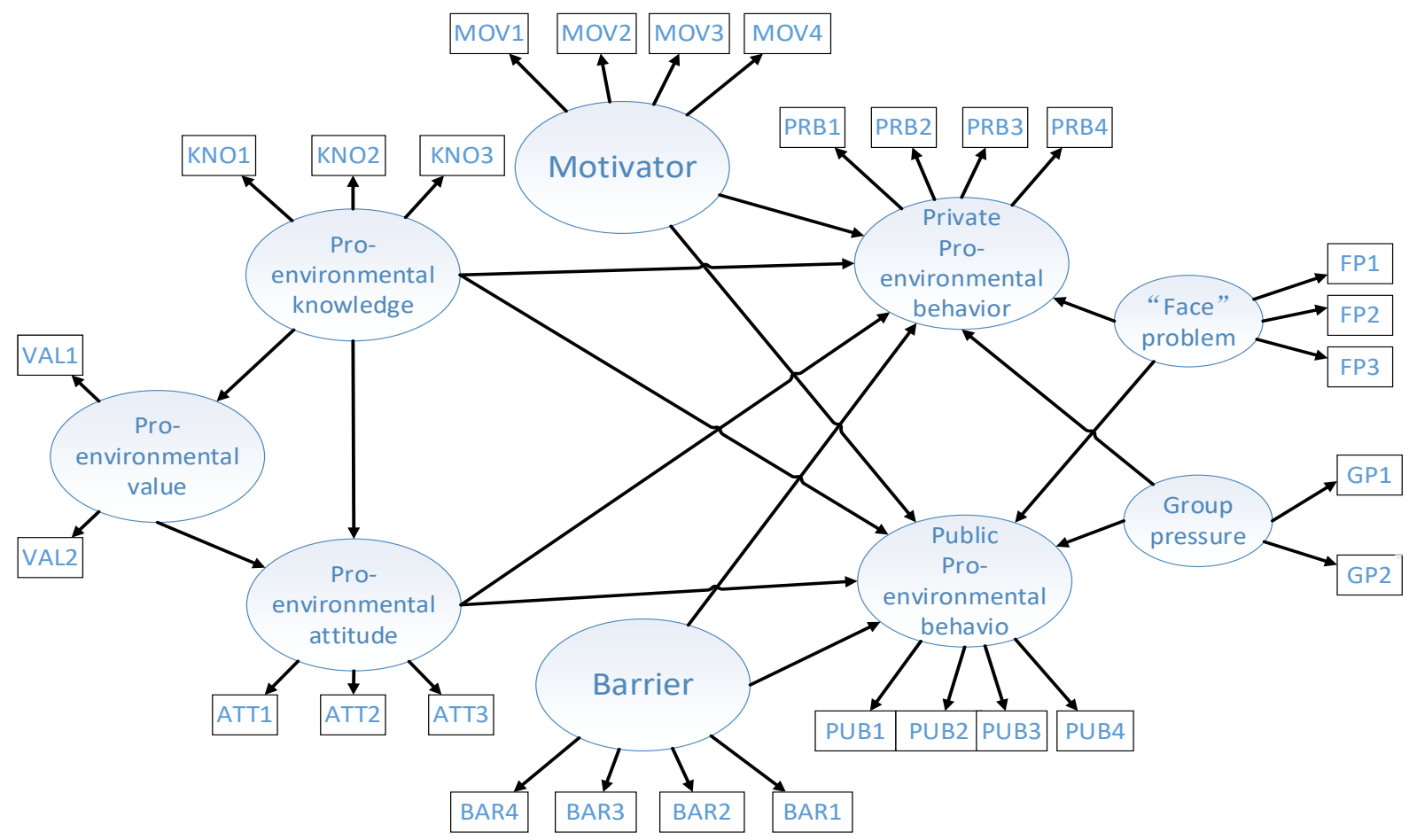

Figure 1. Structural model of constructs and measurement models

\section{THEORETICAL FRAMEWORK}

Goal-framing theory explains three goals of pro-environmental behaviors: hedonic goals, gain goals, and normative goals (Lindenberg and Steg, 2007). However, the Theory of Planned Behaviors (TPB) is often used to explain the relationship between awareness and behaviors, and widespread scientific research has been dedicated to using it to interpret the relationship regarding environmental concerns (Marshall et al., 2010; Paco and Lavrador, 2017; Taufiquea et al., 2016; Zhu et al., 2013). The three most common explanatory variables in the TPB are attitudes, norms, and perceived behavioral control (Schifter and Ajzen, 1985). Attitudes toward environmental protection on green campuses could be described as three types of awareness: pro-environmental knowledge, pro-environmental values, and pro-environmental attitudes (Bai and Liu, 2013). Social norms are "perceived social pressures to perform or not perform a behavior" (Ajzen, 1991).

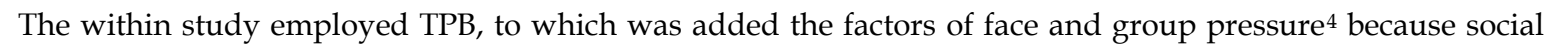
norms regarding these two factors have important roles for individual pro-environmental behaviors on Chinese university campuses. University campuses are microcosms of society, and individuals' pro-environmental awareness and behavior on campuses might be similarly influenced by family, friends, colleagues, cultural values, and relevant policies (Sidiras and Koukios, 2004). The third influential factor is perceived behavioral control, measured by how much impetus or drag that an individual would intend to engage in (Ajzen, 1991). Therefore, some contextual factors and/or personal factors are motivators, barriers, or cultural influences, and this study analyzed them to clarify the reasons for the awareness-behavior gap.

\section{RESULTS}

\section{Descriptive Statistics}

Figure 2 illustrates the extent of the sample's pro-environmental awareness and behaviors by type of stakeholder. There are three important points. First, the mean scores on pro-environmental behaviors ranged from

4 Face problem: "Face" is used metaphorically in a sociological context to mean "reputation" or social standing, particularly in Chinese society (https://en.wikipedia.org/wiki/Face). Group pressure: Redirected from peer pressure, the direct influence on people by peers, or an individual who is encouraged to follow his or her peers and change attitudes, values, or behaviors to conform to those of the influencing group or individual (https://en.wikipedia.org/wiki/Peer_pressure) 


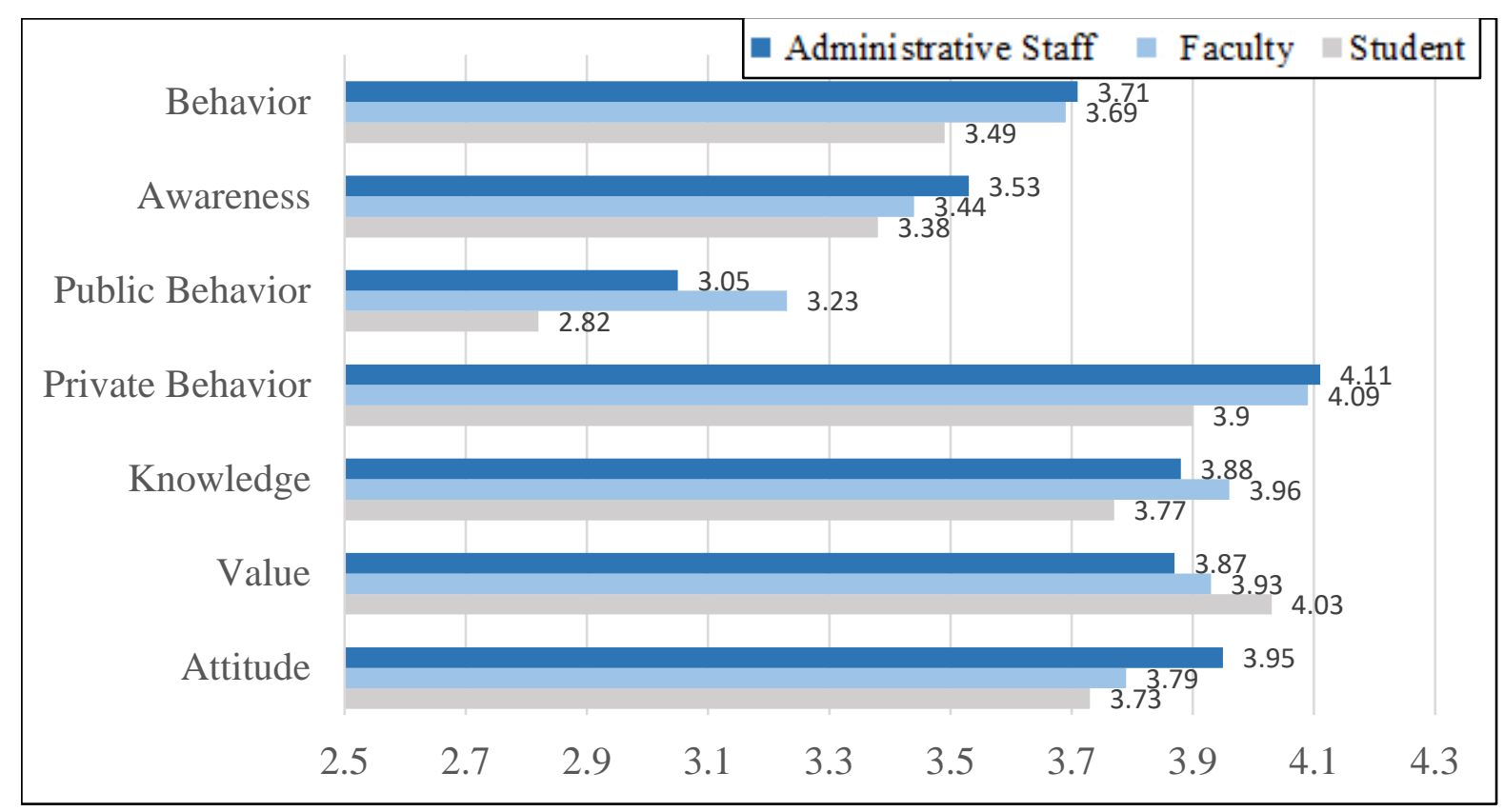

Figure 2. Pro-environmental awareness and behaviors measures of three different groups

3.49 to 3.71 , which was higher than the mean scores on pro-environmental awareness, which ranged from 3.38 to 3.53. Mean private pro-environmental behavior, which ranged from 3.90 to 4.11, was much higher than the mean scores on public pro-environmental behavior, which ranged from 2.82 to 3.05 . The mean of a five-point scale is 3.0 and scores above 3.0 were considered high.

Most respondents preferred public transportation for long trips and low-carbon vehicles, such as bicycles, for short trips, and they preferred to control their daily behaviors by not littering and by not using wooden chopsticks. But in the circumstance of a whole university, which should be considered as a more suitable communication platform than society, However, all of the respondents did not "discuss," "encourage," or "volunteer in" proenvironmental behaviors.

Regarding the extent of pro-environmental awareness, the three types of stakeholders had high levels of awareness (the awareness means of three groups are 3.38, 3.44, and 3.53 respectively). The mean score on proenvironmental knowledge was highest for faculty members at 3.96. The mean score on pro-environmental values among students was 4.03 , which was highest of the three groups, and the mean on pro-environmental attitudes was the highest at 3.95, which was among the administrators. The mean pro-environmental awareness and behavior scores of administrators were highest, whereas the mean pro-environmental awareness and behavior scores of the students were lowest.

Figure 3 compares the mean scores on barriers and motivators across the types of stakeholders. Motivators were more likely than barriers to be reported by all three types (3.51-3.57 versus $2.88-3.10)$. The respondents reported that motivators, such as lowering the cost of living and financial incentives, encouraged their pro-environmental behaviors. The barriers of high cost, lack of skill, and inconvenience were the respondents' main considerations. 


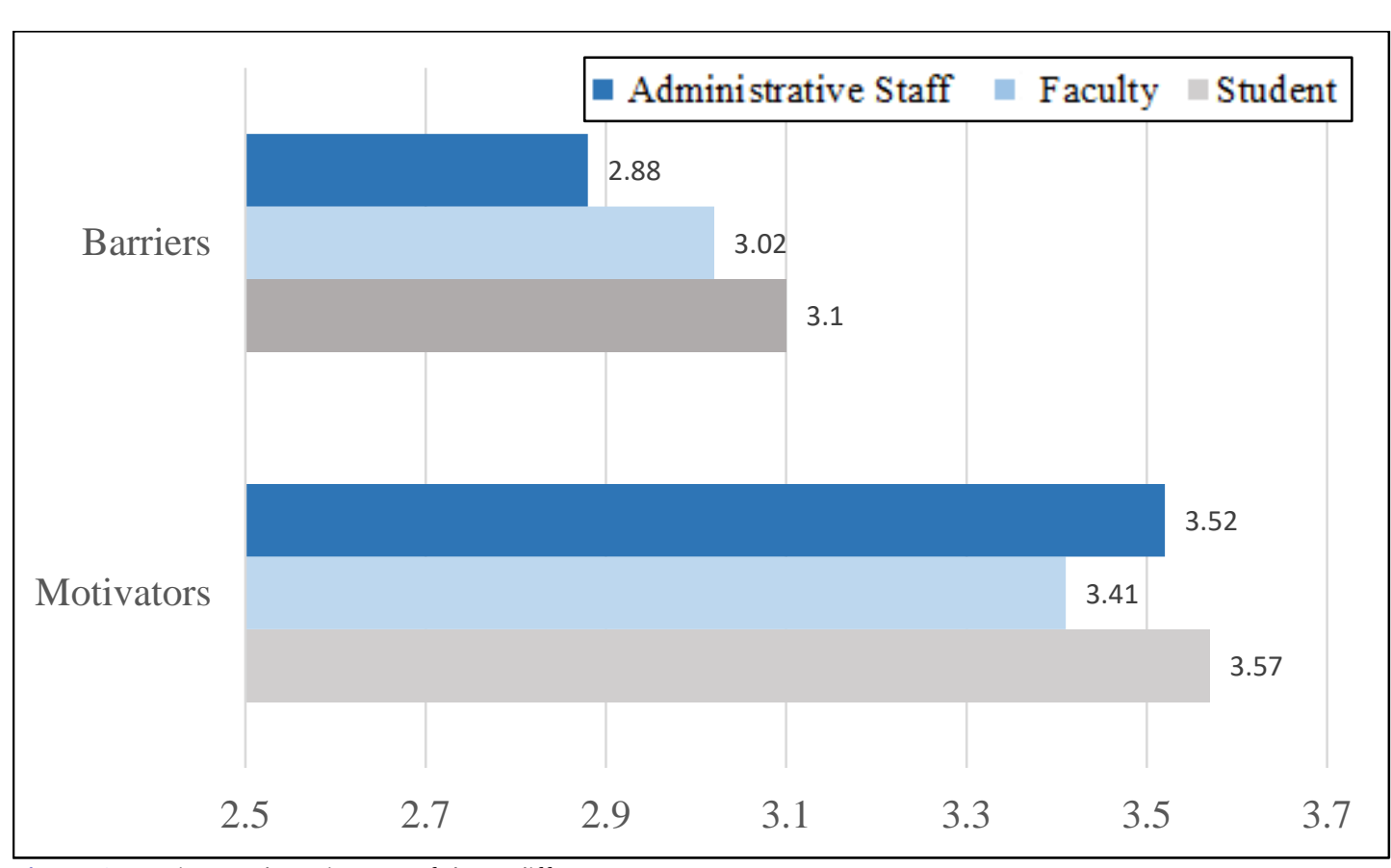

Figure 3. Barriers and Motivators of three different groups

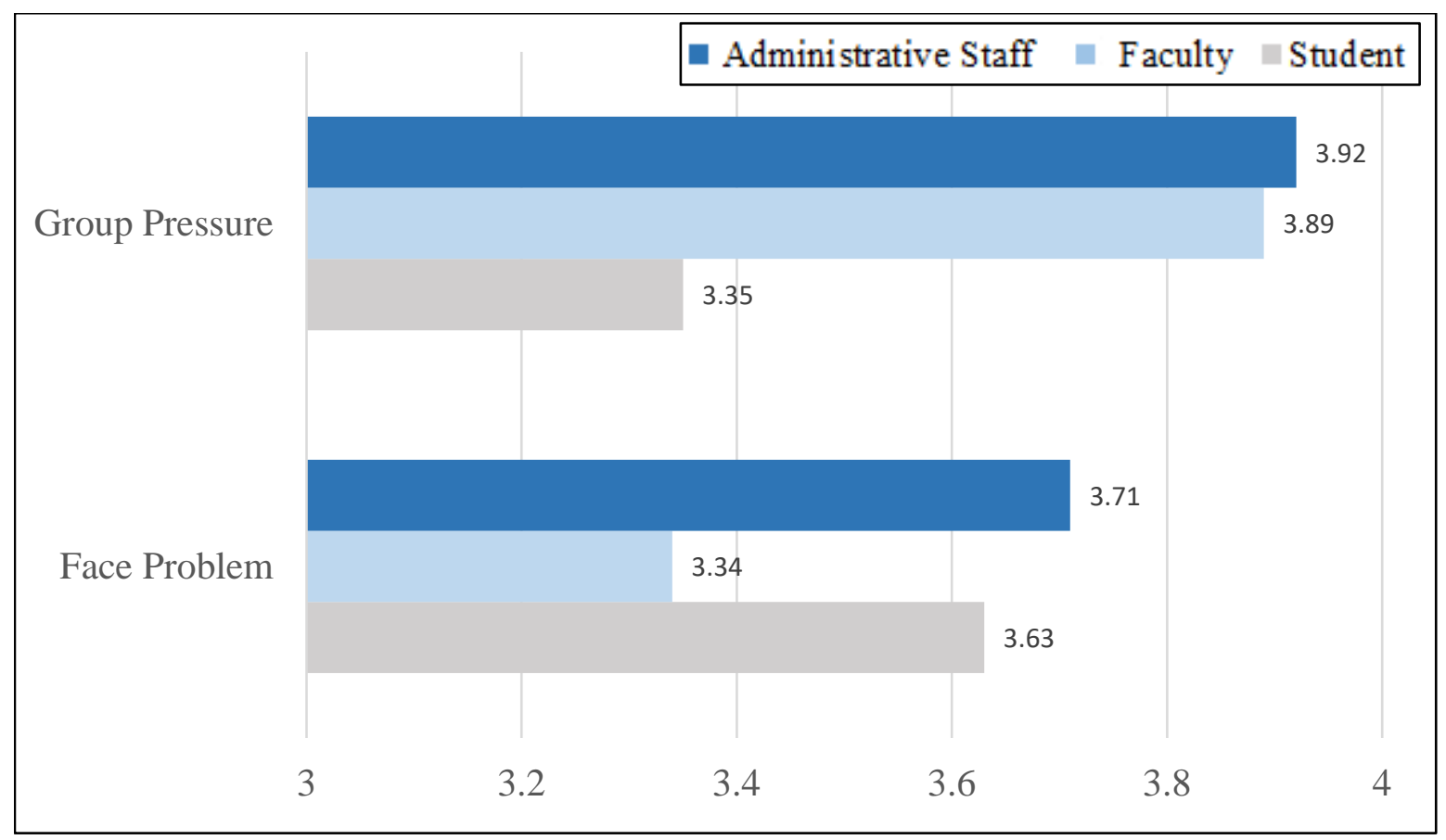

Figure 4. Cultural norms of three different groups

Figure 4 illustrates the mean scores on face and group pressures across the three types of stakeholders, all of which were 3.34 or higher, suggesting strong agreement with the questionnaire items across the groups. The highest means were among the administrators, which averaged 3.71 on face and 3.92 on group pressure. Students' mean score of 3.63 on face was higher than faculty members' mean score of 3.34, but faculty members scored higher on average than students on group pressure (3.89 and 3.35, respectively). This finding means that the students in the sample were more likely to report that face was important in that it was humiliating to collect empty water bottles to sell or that it was humiliating when food was left on the table when entertaining friends. The faculty members were relatively more influenced by group pressure because of conformity.

It is ironic in the previous studies that pro-environmental awareness did not significantly correlate with proenvironmental behavior and these previous studies explained the gap as mainly caused by barriers, such as high 


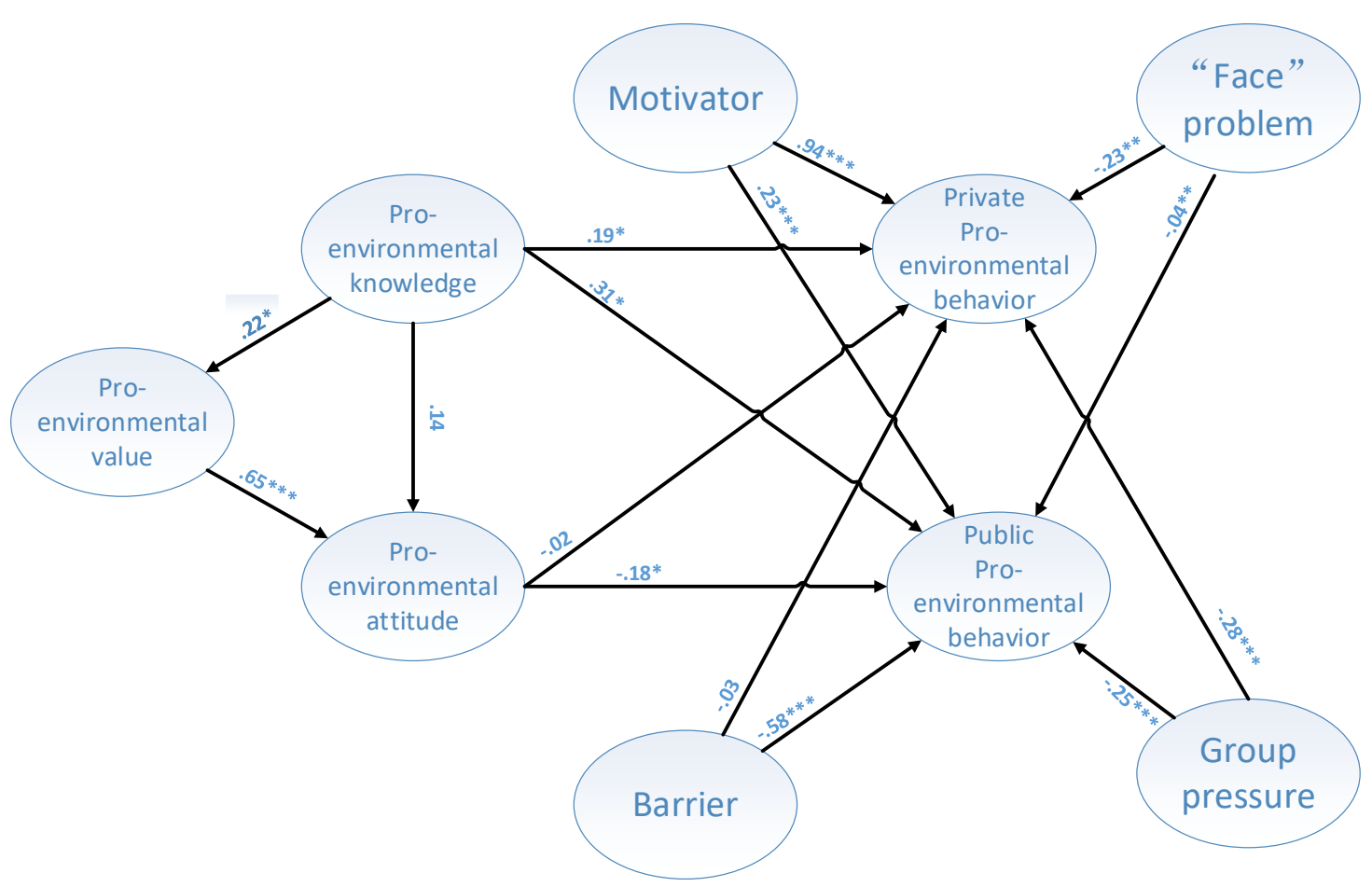

Figure 5. Structural equation model of factors influences on pro-environmental behaviors

cost, to this behavior. In this study, motivators played an important part in influencing pro-environmental behaviors. Moreover, the three types of stakeholders were differently influenced by the cultural factors, which was further analyzed using SEM.

\section{SEM Results}

A comparison among the three groups was performed to clarify the stakeholders' pro-environmental attitudes and behaviors. Figure 5 and Table 4 present the results of the SEM analysis of the entire sample $(n=885)$, which was estimated using AMOS Graphics 17.0 software program (Arbuckle, 2010). Figure 5 illustrates the relationships among the variables and Table 4 provides the statistics, including the factor loadings, standardized coefficients of the direct and indirect effects of the variables on each other, and the model fit indices. The Chi-square test was statistically significant, the Comparative Fit Index was 0.95, and the Root Mean Squared Error of Approximation was just beneath the thresholds of 0.06 .

Although the statistical significance of the path coefficients supports the hypothesis (H1) that proenvironmental values positively influence pro-environmental attitudes (beta $=.65, p<.001$ ), pro-environmental attitudes were not significantly related to private pro-environmental behavior (beta $=-0.02$.) and had a weak significant effect on public pro-environmental behavior (beta $=-0.18, p<0.05$ ). This finding implies that the attitudebehavior gap might be due to external factors, such as motivators, barriers, and cultural norms (Van Raaij and Verhallen, 1983). 
Table 4. SEM results of direct effects, indirect effects, and total effects of hypothesized relationships with model fit indices (standardized coefficients)

\begin{tabular}{|c|c|c|c|c|}
\hline Dependent variable & Independent variable & Direct effect & Indirect effect & Total effect \\
\hline \multirow{7}{*}{ Private pro-environmental behavior } & Values & & -0.030 & -0.030 \\
\hline & Attitudes & -0.018 & & -0.018 \\
\hline & Knowledge & $0.190^{\star}$ & -0.007 & $0.183^{*}$ \\
\hline & Barriers & -0.030 & & -0.030 \\
\hline & Motivators & $0.938^{* * *}$ & & $0.938^{* * *}$ \\
\hline & Face & $-0.230^{\star \star}$ & & $-0.230^{\star \star}$ \\
\hline & Group pressure & $-0.280^{\star \star \star}$ & & $-0.280^{\star \star \star}$ \\
\hline \multirow{7}{*}{ Public pro-environmental behavior } & Value & & $-0.079^{*}$ & $-0.079 *$ \\
\hline & Attitudes & $-0.180^{*}$ & & $-0.180^{*}$ \\
\hline & Knowledge & $0.310^{*}$ & -0.030 & $0.307^{*}$ \\
\hline & Barriers & $-0.580^{\star \star \star}$ & & $-0.580^{\star \star \star}$ \\
\hline & Motivators & $0.230^{\star * *}$ & & $0.230^{\star \star \star}$ \\
\hline & Face & $-0.040^{\star *}$ & & $-0.040^{\star *}$ \\
\hline & Group pressure & $-0.250^{\star \star \star}$ & & $-0.250^{\star \star \star}$ \\
\hline Values & Knowledge & $0.220^{*}$ & & $0.220^{*}$ \\
\hline \multirow{2}{*}{ Attitudes } & Values & $0.650^{* * *}$ & & $0.650^{* * *}$ \\
\hline & Knowledge & 0.140 & 0.130 & 0.270 \\
\hline \multirow{3}{*}{ Model fit } & \multicolumn{4}{|c|}{$\chi^{2} / \mathrm{df}=3.460, p<.05$} \\
\hline & \multicolumn{4}{|c|}{ Comparative Fit Index $(\mathrm{CFI})=0.950$} \\
\hline & \multicolumn{4}{|c|}{ RMSEA $=0.059$} \\
\hline
\end{tabular}

$$
{ }^{*}=\mathrm{p}<.05,{ }^{* *}=\mathrm{p}<.01,{ }^{* * *}=\mathrm{p}<.001
$$

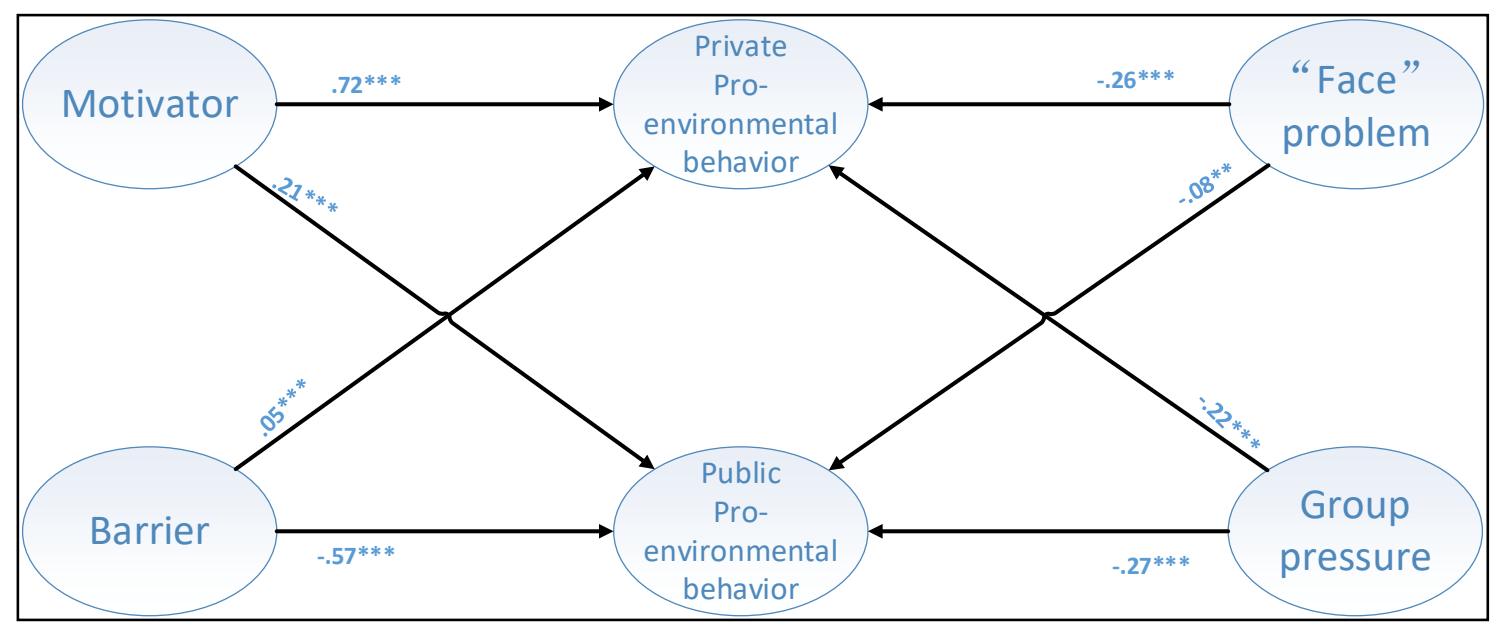

Figure 6. Structural equation model of external factor of motivator, barrier, face problem and group on pro-environmental behaviors in terms of administrators

\section{Comparisons of Influential Factors among Types of Stakeholders}

Figures 6 through 8 illustrate the effects of motivators, barriers, face, and group pressure on private and public pro-environmental behaviors separately for the administrators, faculty members, and students in the sample. All of these relationships were statistically significant for the three types of stakeholders. The barriers did not exert significant effects on private pro-environmental behaviors and had weak effects on public pro-environmental behavior. Regarding motivators, face, and group pressure, the relationships support the hypotheses that motivators increase private and public pro-environmental behaviors among the three groups $(\mathrm{H}$ ) $)$ and that face and group pressure decrease private and public pro-environmental behaviors ( $\mathbf{H 6}$ and $\mathbf{H 7}$, respectively). Comparisons of the effects of motivators to those of barriers might help to explain why private pro-environmental behaviors were more likely than public pro-environmental behaviors due to financial incentives or policy support. The influences of face and group pressures imply that cultural factors are important for understanding the conflicts between people and the natural environment. 


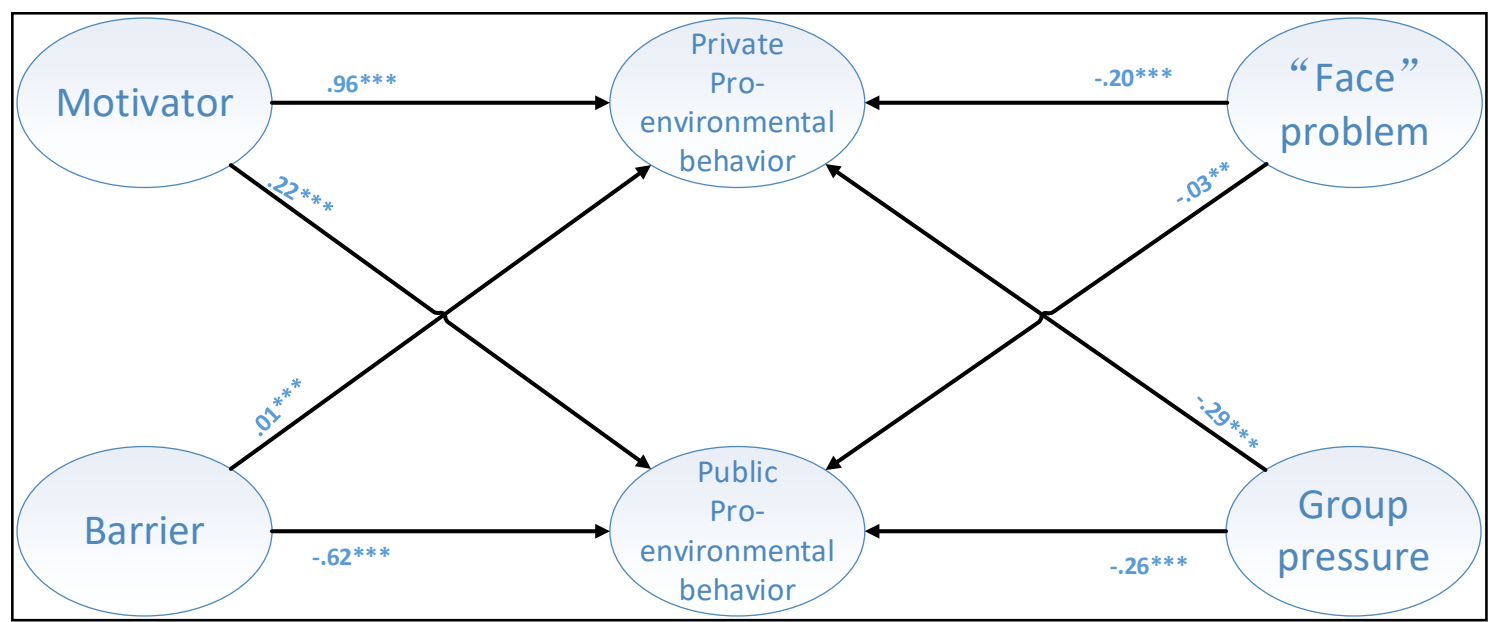

Figure 7. Structural equation model of external factor of motivator, barrier, face problem and group on pro-environmental behaviors in terms of faculties

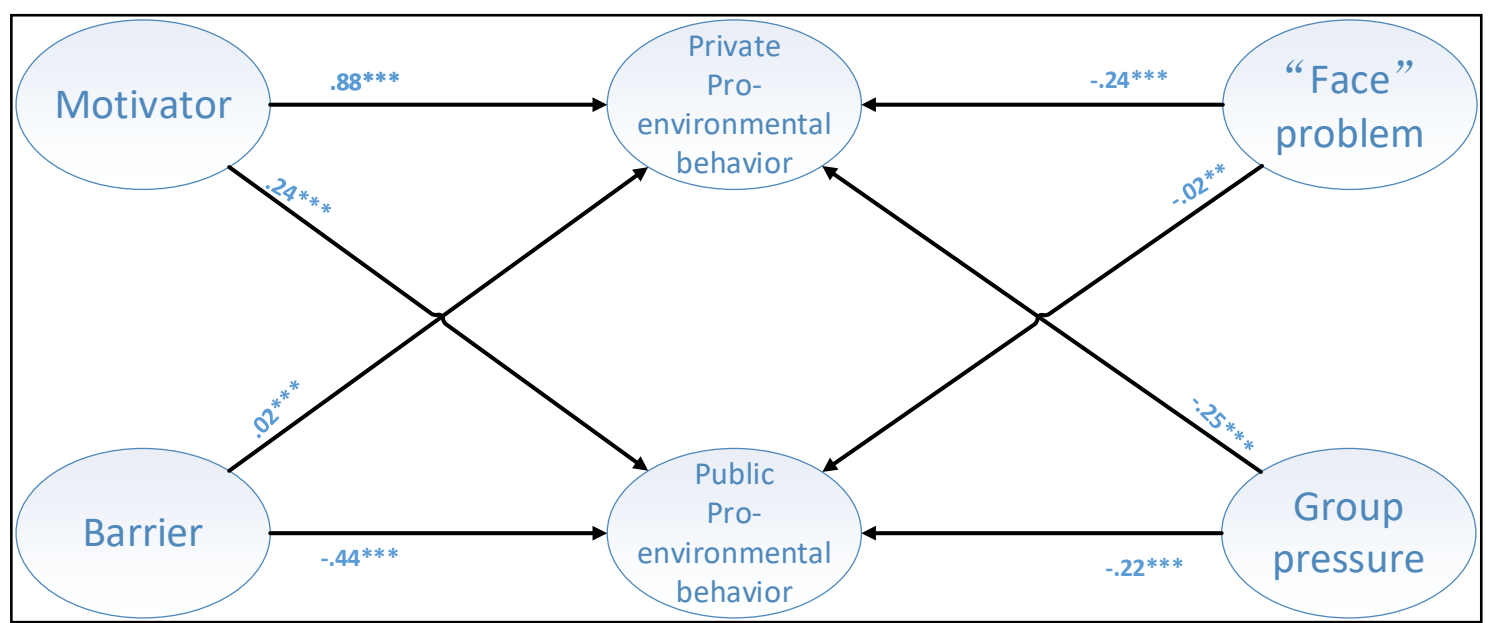

Figure 8. Structural equation model of external factor of motivator, barrier, face problem and group on pro-environmental behaviors in terms of students

Among the administrators in the sample, face had negative significant effects on private behaviors (beta $=-0.26$, $p<.001$ ) and public behaviors (beta $=-.08, p<.01$ ), and group pressure also had negative significant effects on private behaviors (beta $=-0.22, p<.001$ ) and public behaviors (beta $=-0.27, p<.001$ ). Among the faculty members, group pressure appeared more important than face and negatively influenced private behaviors (beta $=-0.29, p<$ .001 ) as well as public behaviors (beta $=-0.26, p<.001$ ). The effects of face were smaller than the effects of group pressure among the students and face negatively influenced private behaviors (beta $=-0.24, p<.001$ ) and public behaviors (beta $=-0.02, p<.01$ ).

\section{DISCUSSION}

The results of this study suggest some interesting and important points to consider. First, the analysis found that pro-environmental behaviors were more common than pro-environmental awareness for all three types of campus stakeholders (students, faculty members, and administrators). This finding supports the results of previous studies of a gap between awareness and behavior. However, opposite to the previous studies (Owens and Driffill, 2008), the pro-environmental awareness was lower than the behavior in Tianjin University.

Furthermore, in this study's sample, barriers were not as strong an influence on private pro-environmental behaviors as were motivators, but were a stronger influence than motivators on public behaviors. Overall, motivators increased private behaviors more than barriers decreased them (beta $=0.94, p<.001$ and -.03 ., respectively), whereas barriers decreased public behaviors more than motivators increased them (beta $=-.58, \mathrm{p}<$ .001 and $.23, p<.001$, respectively). The survey results found a large portion of the sample in agreement with the statements "pro-environmental behaviors could reduce budgets" and "a preference for pro-environmental 
behaviors if policy rewards exist." This result indicates that a financial incentive or policy-related reward might attract people at universities toward private pro-environmental behavior. Previous studies have found that inconvenience and lack of skills were common barriers to pro-environmental behavior. However, in this study's sample, barriers were not the reported causes of not engaging in pro-environmental behaviors (mean scores were $\leq 3)$.

In addition, the analysis considered pro-environmental behaviors as private pro-environmental behaviors and public pro-environmental behaviors. The results found that the extent of private behaviors was greater than the extent of public behaviors. The sample members reported some private behaviors, such as using chopsticks more than once and using public transit or walking for travel, but discussing pro-environmental topics with others or participating in pro-environmental activities was less likely to be reported.

Bai and Liu (2013) pointed out that the reason for this difference is likely China's long-term neglect of lowcarbon development in its context that prioritizes economic development. Low-carbon development has lacked attention and importance, and opportunities for pro-environmental behaviors have been limited. Bai and Liu (2013) concluded that it has been difficult for people to commit to public pro-environmental behaviors. Similarly, a lack of propaganda on low-carbon and pro-environmental development relates to the lack of pro-environmental awareness, which is increasingly considered the reason for the lack of pro-environmental behaviors.

Unlike the rest of the public, people who live on university campuses are normally exposed to proenvironmental education and have been taught it since elementary school. Additionally, the emphasis on promoting green campuses is believed to improve the convenience and ability to discuss pro-environmental topics and develop pro-environmental activities. Yuan et al. (2013) argued that students are more familiar with everyday pro-environmental problems than with ecological pro-environmental issues. Most of this study's students focused on the environmental issues that closely related to their personal interests rather than on the long-term issues. Thus, they did not actively discuss these topics with others. That result supports the idea of a tendency toward strong enforcement of eco-technology outcomes and management of energy facilities rather than the considerations of the green campus movements at foreign universities (Tan et al., 2014), and it supports the notion that a good top-level design is lacking.

The actions of propagating the concept of pro-environment and furthering its nature were less than sufficient. Regarding this problem, the inappropriate pro-environmental publicity and propaganda should be the critical reason.

Universities courses introduce environmental topics and point out the significance of environmental protection. Regarding social activities and propaganda, the focuses typically are on the progress and development of innovations and the pro-environmental technologies. The advancement of green campuses should not stop after improving energy conservation and resource efficiency, but joint participation by students, faculty members, and administrators is needed to further develop the top-level design that is required. Svanström et al. (2008) emphasized that, to protect the essence of sustainable development, more efforts in education and publicity are needed to raise stakeholders' awareness. Activities, such as student organizations and clubs, are needed to increase their awareness because students are key stakeholders in sustainable development (Anand et al., 2015; Fonseca et al., 2011). Adequate discussion in academic forums and project-oriented workshops on environmental issues might influence stakeholders on campus (Filho et al., 2016; Huge et al., 2016). Besides, policy rewards were encouraged to establish to award the expected approvals and appreciations based on the motivators influence.

The new-found predictors in the SEM estimations were face and group pressures. For students, face had the most important role, and group pressure was the primary factor influencing the faculty. Under group pressure, people are likely to abandon pro-environmental behaviors to conform to their groups. On a campus, people live with their group members, and other people's behaviors might be very influential. For example, a person might not want to turn on air conditioning, but they might feel compelled to do so because of other people's attitudes. Similarly, people might feel compelled to choose lifestyles that are not friendly to the environment to gain social acceptance. Most people do not want to be regarded as outsiders and they do not want to bother other people.

Notably, administrators were influenced by face and group pressure, which means that decision-makers and leaders were concerned with reputation and social acceptance. On the one hand, face and group pressure might influence their abilities to model acceptable behavior and to make appropriate decisions. On the other hand, it could also be an opportunity for decision-makers and leaders to completely apply the characteristics of face problem and group pressure to the promotion of personal reputations. Therefore, they were able to combine it with reshaping the universities' pro-environmental images and reputations. Furthermore, administrators might develop a proenvironmental atmosphere to draw attention to the environment because doing so might increase their personal reputations in the group. Some administrators might lack interest in pro-environmental behaviors and in the bureaucratic and hierarchical administrative system (Zhao and Zou, 2015), so establishing an effective way to communicate or regular trainings for faculty and staff might promote collaborative and collective decision-making to influence awareness of and attitudes toward environmental issues. 


\section{CONCLUSIONS}

Global climate and ecological changes are causing serious environmental crises around the world, and sustainable development had become a topic that occupies significant worldwide attention. China has actively aimed to achieve sustainable development through strategic plans and with the governmental policy of "ecological civilization construction." The pivotal role of post-secondary education for promoting sustainable development is in the developmental processes of people's awareness and behaviors and in the publicity on ecological culture. Because numerous environmental issues, such as global warming, smog, and water pollution, are rooted in human behaviors (Pappas et al., 2015), this study considered private and public pro-environmental behaviors and attempted to construct dimensions thereof (knowledge, values, and attitudes). Motivations and barriers were analyzed as external forces and the social factors were face (reputation) and group pressure. Using these constructs, this study investigated the reasons for engaging or not in pro-environmental behaviors by students, faculty members, and administrators. The analysis found: (1) the respondents were more likely to engage in proenvironmental behaviors than to have awareness of them, (2) private behaviors were more likely than public behaviors, (3) motivations had stronger effects than barriers had on behaviors, and (4) face and group pressure were important factors, particularly for administrators.

The results of this study might be a valuable reference for policymaking on environmental issues at university campuses in China. By examining students, faculty members, and administrators separately, this study customized relevant solutions to the different stakeholder groups on campuses. This study focused on the extents of the effects of factors, internal and external, across the groups with distinct statuses and positions on campus.

In the green campus developmental process, administrators have the essential role of policymaker. This group's pro-environmental behaviors were influenced in this study by face and group pressure, and they are in a position to influence others' behavioral conformity regarding pro-environmental behaviors. Faculty members' proenvironmental behaviors were significantly influenced by group pressure, and they are expected to improve their courses by infusing an awareness of environmental protections and to disseminate pro-environmental ideas. People who are responsible for the environment should have environment-friendly attitudes so that they can actively and carefully perform pro-environmental behaviors. Their emotions are expected to influence their behaviors, meaning that they might feel uncomfortable if they were to behave inappropriately, which might encourage them to take pro-environmental steps. Transformative factors related to cultural values and institutional practices are needed to strengthen pro-environmental attitudes and behaviors (Bina et al., 2016).

Students' pro-environmental behaviors were influenced more than the other groups by face. Thus, the students in the sample apparently needed relatively more social approval (on average) or that they placed relatively more value on it. The students were sensitive to the gain or loss of face, which somewhat determined their attitudes and behaviors. Therefore, it is important to develop a pro-environmental culture on campuses in addition to increasing educational efforts and propaganda.

Particular attention should be paid to variation in the characteristics of distinct groups and to emphasis on the strategic significance of pro-environmental attitudes and behaviors at the national level. At the university level, it might be effective to combine teaching of professional knowledge and introducing pro-environment atmosphere. Through this approach, students might improve their understanding of the relationship between their major courses and environmental issues. They might directly learn about the environment instead of just obtaining information on upgrades to existing pro-environmental technologies, which might improve their understanding and sense of responsibility for protecting the environment. Students are expected to cultivate a spirit of practice and communication, and they are encouraged to develop relationships in student unions, communities, and social pro-environmental organizations while they are at university, which is a diverse setting. Pro-environmental activities are excellent opportunities for students because, while promoting personal environmental awareness, they learn about and communicate relevant information to other students. Students should influence each other with their personal attitudes and behaviors, and they should take social responsibility for sharing and practicing environmental morality.

The methodology of this study had limitations because the sample was drawn from one university, despite the relatively large sample size. Another limitation was that the data were self-reports rather than observations. Future research that follows up on disseminating pro-environmental ideas is important. For example, periodic follow-up surveys could assess change over time and determine the extent to which pro-environmental awareness and behaviors increased, which would help policymakers adjust their approaches on campuses and help them to target their publicity on sustainability.

\section{ACKNOWLEDGEMENT}

This work was supported by National Social Science Funds (NSSF) grant numbers 15AGL024. 


\section{REFERENCES}

Abdul-Wahab, S. A. (2010). Level of environmental awareness towards depletion of the ozone layer among distributors and consumers in the solvent sector: a case study from Oman. Climatic Change, 103(3-4), 503517.

Abrahamse, W., Steg, L., Vlek, C., \& Rothengatter, T. (2007). The effect of tailored information, goal setting, and tailored feedback on household energy use, energy-related behaviors, and behavioral antecedents. Journal of Environmental Psychology, 27(4), 265-276.

Ajzen, I. (1985). From Intentions to Actions: A Theory of Planned Behavior. Berlin, Heidelberg: Springer.

Ajzen, I. (1991). The theory of planned behavior. Organizational Behavior and Human Decision Processes, 50(2), 179211.

Anand, C. K., Bisaillon, V., Webster, A., \& Amor, B. (2015). Integration of sustainable development in higher education: a regional initiative in Quebec (Canada). Journal of Cleaner Production, 108, 916-923.

Arbuckle, J. L. (2010). Amos19.0. Chicago, IL: Amos Development Corporation.

Axsen, J., \& Kurani, K. S. (2012). Social influence, consumer behavior, and low-carbon energy transitions. Annual Review of Environment and Resources, 37, 311-340.

Azucena Vicente-Molina, M., Fernandez-Sainz, A., \& Izagirre-Olaizola, J. (2013). Environmental knowledge and other variables affecting pro-environmental behaviour: comparison of university students from emerging and advanced countries. J. Clean. Prod., 61, 130-138.

Baas, L., \& Hjelm, O. (2015). Support your future today: enhancing sustainable transitions by experimenting at academic conferences. J. Clean. Prod., 98,1-7.

Bai, Y., \& Liu, Y. (2013). An exploration of residents' low-carbon awareness and behavior in Tianjin, China. Energy Policy, 61, 1261-1270.

Bamberg, S. (2003). How does environmental concern influence specific environmentally related behaviors? A new answer to an old question. Journal of Environmental Psychology, 23(1), 21-32.

Barber, N., Taylor, C., \& Strick, S. (2009). Wine consumers' environmental knowledge and attitudes: influence on willingness to purchase. Int. J. Wine Res., 1, 59-72.

Barr, S. (2003). Strategies for sustainability: citizens and responsible environmental behaviour. Area, 35(3), $227-240$.

Barr, S. (2007). Factors influencing environmental attitudes and behaviors: a UK case study of household waste management. Environment and Behavior, 39(4), 435-473.

Bayulken, B., \& Huisingh, D. (2015). Perceived ‘Quality of Life' in eco-developments and in conventional residential settings: an explorative study. Journal of Cleaner Production, 98, 253-262.

Bina, O., Balula, L., Varanda, M., \& Fokdal, J. (2016). Urban studies and the challenge of embedding sustainability: a review of international master programmes. J. Clean. Prod., 137, 330-346.

Bohner, G., \& Dickel, N. (2011). Attitudes and attitude change. Annual Review of Psychology, 62, 391-417.

Brown, P., \& Levinson, S. C. (1987). Politeness: Some Universals in Language Usage. Cambridge University Press.

Byrne, B. M. (2001). Structural equation modeling with AMOS, EQS, and LISREL: comparative approaches to testing for the factorial validity of a measuring instrument. International Journal of Testing, 1(1), 55-86.

Carey, P. (2013). Student engagement: stakeholder perspectives on course representation in university governance. Studies in Higher Education, 38(9), 1290-1304.

Chan, D. Y.-L., Yang, K.-H., Lee, J.-D., \& Hong, G.-B. (2010). The case study of furnace use and energy conservation in iron and steel industry. Energy, 35(4), 1665-1670.

Chan, R. Y. K. (2001). Determinants of Chinese consumers' green purchase behavior. Psychology E Marketing, 18(4), 389-413.

China Green University Network (CGUN) (2013). Introduction of China Green University Network. www.cgun.org/en

Churchill, Jr., G. A. (1979). A paradigm for developing better measures of marketing constructs. Journal of Marketing Research, 16, 64-73.

Clark, C. F., Kotchen, M. J., \& Moore, M. R. (2003). Internal and external influences on pro-environmental behavior: participation in a green electricity program. J. Environ. Psychol., 23(3), 237-246.

Clauss-Ehlers, C. S., \& Parham, W. D. (2014). Landscape of diversity in higher education: linking demographic shifts to contemporary university and college counseling center practices. Journal of Multicultural Counseling and Development, 42(2), 69-76. 
Cotton, D., Shiel, C., \& Paco, A. (2016). Energy saving on campus: a comparison of students' attitudes and reported behaviours in the UK and Portugal. J. Clean. Prod., 129, 586-595.

Creech, H., McDonald, C., \& Kahlke, P. M. H. (2009). Measuring Knowledge, Attitudes and Behaviors Towards Sustainable Development: Two Exploratory Studies. Winnipeg CA: International Institute for Sustainable Development.

Daae, J., \& Boks, C. (2015). A classification of user research methods for design for sustainable behaviour. J. Clean. Prod., 106, 680-689.

Dagiliute, R., \& Liobikiene, G. (2015). University contributions to environmental sustainability: challenges and opportunities from the Lithuanian case. J. Clean. Prod., 108, 891-899.

Dunlap, R. E., VanLiere, K. D., Mertig, A. G., \& Jones, R. E. (2000). New trends in measuring environmental attitudes: measuring endorsement of the new ecological paradigm: a revised NEP scale. Journal of Social Issues, 56, 425-442.

Emelyanova, N., \& Voronina, E. (2014). Introducing a Learning Management System at a Russian University: Students' and Teachers' Perceptions. International Review of Research in Open and Distance Learning, 15(1).

Fernandez-Manzanal, R., Serra, L. M., Morales, M. J., Carrasquer, J., Rodriguez-Barreiro, L. M., del Valle, J., \& Murillo, M. B. (2015). Environmental behaviours in initial professional development and their relationship with university education. J. Clean. Prod., 108, 830-840.

Filho, W. L., Shiel, C., \& Paco, A. (2016). Implementing and operationalising integrative approaches to sustainability in higher education: the role of project-oriented learning. J. Clean. Prod., 133, 126-135.

Fonseca, A., Macdonald, A., Dandy, E., \& Valenti, P. (2011). The state of sustainability reporting at Canadian universities. International Journal of Sustainability in Higher Education, 12(1), 22-40.

Hair, J. F., Black, W. C., Babin, B. J., Anderson, R. E., \& Tatham, R. L. (2010). Multivariate Data Analysis. Upper Saddle River, NJ: Prentice Hall.

Hu, X., \& Wang, J. (2014). The impact mechanism between the consciousness of face and public resource-saving behavior: an exploration of the theoretical model. Journal of Chongqing University of Arts and Sciences (Social Sciences Edition), 33(3), 85-90.

Huge, J., Block, T., Waas, T., Wright, T., \& Dahdouh-Guebas, F. (2016). How to walk the talk? developing actions for sustainability in academic research. J. Clean. Prod., 137, 83-92.

Isljamovic, S., Petrovic, N., \& Jeremic, V. (2011). Technology enhanced learning as a key component of increased environmental awareness amongst students from the University of Belgrade. Technics Technologies Education Management-Item, 6(4), 1175-1181.

Jager, W. (2006). Stimulating the diffusion of photovoltaic systems: a behavioural perspective. Energy Policy, 34(14), 1935-1943.

Kaplowitz, M. D., Thorp, L., Coleman, K., \& Kwame Yeboah, F. (2012). Energy conservation attitudes, knowledge, and behaviors in science laboratories. Energy Policy, 50, 581-591.

Koger, S. M., \& Winter, D. N. (2011). The Psychology of Environmental Problems: Psychology for Sustainability. Psychology Press.

Kollmus, A., \& Agyeman, J. (2002). Mind the gap: why do people act environmentally and what are the barriers to pro-environmental behavior? Environmental Education Research, 8(3), 239-260.

Lin, P.-C., \& Huang, Y.-H. (2012). The influence factors on choice behavior regarding green products based on the theory of consumption values. J. Clean. Prod., 22, 11-18.

Lindenberg, S., \& Steg, L. (2007). Normative, gain and hedonic goal frames guiding environmental behavior. Journal of Social Issues, 63(1), 117-137.

Lozano, R. (2006). Incorporation and institutionalization of SD into universities: breaking through barriers to change. J. Clean. Prod., 14(9-11), 787-796.

Lozano, R. (2010). Diffusion of sustainable development in universities' curricula: an empirical example from Cardiff University. J. Clean. Prod., 18(7), 637-644.

Lukman, R., Lozano, R., Vamberger, T., \& Krajnc, M. (2013). Addressing the attitudinal gap towards improving the environment: a case study from a primary school in Slovenia. J. Clean. Prod., 48, 93-100.

Maniatis, P. (2016). Investigating factors influencing consumer decision-making while choosing green products. J. Clean. Prod., 132, 215-228. 
Marshall, R., Akoorie, M., Hamann, R., \& Sinha, P. (2010). Environmental practices in the wine industry: an empirical application of the theory of reasoned action and stakeholder theory in the United States and New Zealand. Journal of World Business, 45(4), 405-414.

Martinsson, J., Lundqvist, L. J., \& Sundstrom, A. (2011). Energy saving in Swedish households: the (relative) importance of environmental attitudes. Energy Policy, 39(9), 5182-5191.

Mu, R. M., Liu, P., Song, Y. T., Cao, D. Y., Zhan, L. W., Zuo, J., \& Yuan, X. L. (2015). Theory and practice of sustainability in higher education: from the perspective of Green University. Proceedings of the 2015 AsiaPacific Energy Equipment Engineering Research Conference, 9, 484-487.

Nunnally, J. C. (2010). Psychometric Theory. Tata McGraw-Hill Education.

Oguz, D., Cakci, I., \& Kavas, S. (2010). Environmental awareness of university students in Ankara, Turkey. African Journal of Agricultural Research, 5(19), 2629-2636.

Olson, J. M., \& Zanna, M.P. (1993). Attitudes and attitude change. Annual Review of Psychology, 44, 117-154.

Owens, S., \& Driffill, L. (2008). How to change attitudes and behaviours in the context of energy. Energy Policy, 36, 4412-4418.

Ozaki, R., \& Sevastyanova, K. (2011). Going hybrid: an analysis of consumer purchase motivations. Energy Policy, 39(5), 2217-2227.

Paco, A., \& Lavrador, T. (2017). Environmental knowledge and attitudes and behaviours towards energy consumption. Journal of Environmental Management, 197, 384-392.

Pappas, E., Pappas, J., \& Sweeney, D. (2015). Walking the walk: conceptual foundations of the Sustainable Personality. J. Clean. Prod., 86, 323-334.

Polonsky, M. J., Vocino, A., Grau, S. L., Garma, R., \& Ferdous, A. S. (2012). The impact of general and carbon related environmental knowledge on attitudes and behaviour of US consumers. J. Mark. Manage., 28, 238-263.

Raymond, C. M., Fazey, I., Reed, M. S., Stringer, L. C., Robinson, G. M., \& Evely, A. C. (2010). Integrating local and scientific knowledge for environmental management. Journal of Environmental Management, 91(8), 1766-1777.

Rodriguez-Barreiro, L. M., Fernandez-Manzanal, R., Serra, L. M., Carrasquer, J., Murillo, M. B., Morales, M. J., \& del Valle, J. (2013). Approach to a causal model between attitudes and environmental behaviour: a graduate case study. J. Clean. Prod., 48, 116-125.

Rokeach, M. (1973). The Nature of Human Values. New York: Free Press.

Sabbaghia, M., Behdadb, S., \& Zhuanga, J. (2016). Managing consumer behavior toward on-time return of the waste electrical and electronic equipment: a game theoretic approach. Int. J. Prod. Econ., 182, 545-563.

Schahn, J., \& Holzer, E. (1990). Studies of individual environmental concern: the role of knowledge, gender, and background variables. Environment and Behavior, 22(6), 767-786.

Schifter, D. E., \& Ajzen, I. (1985). Intention, perceived control, and weight loss: an application of the theory of planned behavior. Journal of Personality and Social Psychology, 49(3), 843-851.

Sidiras, D. K., \& Koukios, E. G. (2004). Solar systems diffusion in local markets. Energy Policy, 32(18), $2007-2018$.

Spencer-Oatey, H. (2002). Managing rapport in talk: using rapport sensitive incidents to explore the motivational concerns underlying the management of relations. Journal of Pragmatics, 34(5), 529-545.

Steg, L. (2008). Promoting household energy conservation. Energy Policy, 36(12), 4449-4453.

Steg, L., \& Vlek, C. (2009). Encouraging pro-environmental behaviour: an integrative review and research agenda. Journal of Environmental Psychology, 29(3), 309-317.

Stern, P. (2000). Toward a coherent theory of environmentally significant behavior. Journal of Social Issues, 56(3), 407-424.

Sun, M., Yang, X., Huisingh, D., Wang, R., \& Wang, Y. (2015). Consumer behavior and perspectives concerning spent household battery collection and recycling in China: a case study. J. Clean. Prod., 107, 775-785.

Svanström, M., Lozano-García, F. J., \& Rowe, D. (2008). Learning outcomes for sustainable development in higher education. International Journal of Sustainability in Higher Education, 9(3), 339-351.

Tan, H. W., Chen, S. Q., Shi, Q., \& Wang, L. L. (2014). Development of green campus in China. J. Clean. Prod., 64, 646-653.

Tarah, S. A. W. (2007). Developing research priorities with a cohort of higher education for sustainability experts. International Journal of Sustainability in Higher Education, 8(1), 34-43.

Taufiquea, K., Siwarb, C., Chamhuric, N., \& Hasan, S. (2016). Integrating general environmental knowledge and eco-label knowledge in understanding ecologically conscious consumer behaviour. Procedia Econ. Finance, $37,39-45$. 
Thompson, S. C. G., \& Barton, M. A. (1994). Ecocentric and anthropocentric attitudes toward the environment. Journal of Environmental Psychology, 14(2), 149-157.

Turaga, R. M. R., Howarth, R. B., \& Borsuk, M. E. (2010). Pro-environmental behavior. Ann. N. Y. Acad. Sci., 1185(1), 211-224.

Van Raaij, W. F., \& Verhallen, T. M. M. (1983). A behavioral model of residential energy use. Journal of Economic Psychology, 3(1), 39-63.

Wang, Y., Shi, H., Sun, M., Huisingh, D., Hansson, L., \& Wang, R. (2013). Moving towards an ecologically sound society? starting from green universities and environmental higher education. J. Clean. Prod., 61, 1-5.

Wang, Y., \& Yang, Z. (2005). A literature review of face. Psychological Science, 28(2), 398-440.

Wright, H. A., Ironside, J. E., \& Gwynn-Jones, D. (2008). The current state of sustainability in bioscience laboratories: a statistical examination of a UK tertiary institute. International Journal of Sustainability in Higher Education, 9(3), 282-294.

Wright, T. (2010). University presidents' conceptualizations of sustainability in higher education. International Journal of Sustainability in Higher Education, 11(1), 61-73.

$\mathrm{Yu}, \mathrm{W}$. (2009). Formation mechanism of green consumption behavior analysis based on the perspective of population pressure and environmental cognition. Consumer Economics, 4, 75-77.

Yuan, X., Zuo, J., \& Huisingh, D. (2013). Green universities in China: what matters? J. Clean. Prod., 61, 36-45.

Zhao, W. X., \& Zou, Y. H. (2015). Green university initiatives in China: a case of Tsinghua University. International Journal of Sustainability in Higher Education, 16(4), 491-506.

Zhu, Q., Li, Y., Geng, Y., \& Qi, Y. (2013). Green food consumption intention, behaviors and influencing factors among Chinese consumers. Food Quality and Preference, 28(1), 279-286.

Zsoka, A. N. (2008). Consistency and "awareness gaps" in the environmental behaviour of Hungarian companies. J. Clean. Prod., 16(3), 322-329.

Zsoka, A., Szerenyi, Z. M., Szechy, A., \& Kocsis, T. (2013). Greening due to environmental education? environmental knowledge, attitudes, consumer behavior and everyday pro-environmental activities of Hungarian high school and university students. J. Clean. Prod., 48, 126-138.

\section{http://www.ejmste.com}

